\title{
Medicinal attributes of Solanum xanthocarpum fruit consumed by several tribal communities as food: an in vitro antioxidant, anticancer and anti HIV perspective
}

Shashank Kumar and Abhay K Pandey*

\begin{abstract}
Background: Solanum xanthocarpum (Solanaceae) has been used for treatment of many infectious and degenerative diseases in traditional medicine. Present study reports the medicinal efficacy of $S$. xanthocarpum fruit as antioxidant, anticancer and anti HIV agents.

Methods: Extracts were prepared using Soxhlet apparatus and partially characterized by thin layer chromatography (TLC). Total flavonoid content was determined spectrophotometrically. Reducing power, DPPH radical scavenging activity and lipid peroxidation inhibition assays were used for measurement of antioxidant potential. Cytotoxic (SRB assay) and anti-HIV RT inhibition (RT assay kit, Roche) activities were determined using ELISA.

Results: TLC revealed the diversity of phytoconstituents in various sequential extracts of $S$. xanthocarpum fruit. Total flavonoid contents in extracts ranged between 10.22-162.49 $\mu$ g quercetin equivalent/mg. Spectroscopic scanning of water soluble phenolics showed maximum absorbance at 250 and $280 \mathrm{~nm}$. Polar extracts displayed potent radical scavenging activity (>80\%). Several sub-fractions (spots) of extracts separated on TLC plates also exhibited powerful radical scavenging activity. Considerable reducing power was observed in extracts. Hexane fraction provided 55\% lipoprotection in rat kidney homogenate. Non-polar extracts exhibited appreciable cytotoxic activity (70-91\%) against leukemia (THP-1) and lung cancer (HOP-62) cell lines. Lower inhibitory activity was observed in extracts against HIV Reverse Transcriptase enzyme.
\end{abstract}

Conclusion: The study demonstrated considerable antioxidant and anticancer activities in S. xanthocarpum fruit.

Keywords: Antioxidant, Anticancer, DPPH, LPOI, Reducing power, Solanum xanthocarpum, Anti HIV

\section{Background}

Excessive free radicals may produce oxidative stress that can damage lipids, proteins and DNA resulting into various chronic and degenerative diseases and/or disorders such as cancer, cardiovascular, alzheimer and ageing etc. [1]. Human body has several enzymatic and non-enzymatic antioxidant mechanisms to combat oxidative stress. The non enzymatic antioxidants are either produced naturally in the body or supplied through foods and/or supplements. Antioxidants derived from plants are presumed to be safe since they are natural in origin and have capability to counteract the damaging effect of reactive oxygen

* Correspondence: akpandey23@rediffmail.com

Department of Biochemistry, University of Allahabad, Allahabad 211002, India species (ROS) [2]. Phenolics are a group of naturally occurring compounds having functional hydroxyl groups. They have been reported to possess antioxidant and antiviral activities [3]. Free radical scavenging and inhibition of lipid peroxidation are two such mechanisms by virtue of which phenolics may combat the deleterious effect of ROS $[4,5]$.

Oxidative stress induces a cellular redox imbalance which has been observed in various cancer cells. Polyphenols have been shown to inhibit the cancer associated enzyme telomerase, cell cycle and induce apoptosis [6]. Many important anticancer drugs are derived from plant sources, e.g., taxol from Taxus brevifolia and camptothecin from Cascuta reflexa [7]. Compounds having low side 
effects, inducing apoptosis and target specific cytotoxicity to the cancer cells are drugs of choice [8].

Uncontrolled viral replication in CD4 T cells of host body is responsible for pathogenesis of HIV. HIV reverse transcriptase (RT) enzyme is one of the prime targets for the treatment of HIV/AIDS. Inhibitors bind with the active or allosteric site of HIV RT based on their chemical nature whether they are analogs of nucleoside or nonnucleoside, respectively. This interaction may significantly reduce morbidity and mortality of HIV infected patients [9]. Several anti-HIV phytoconstituents of plant origin are known which include drymaritin (an alkaloid), diandraflavone, torosaflavone $\mathrm{A}$, and cis-p-coumarate derived from a weed Drymaria diandra [10]. Phytoconstituents present in natural food items especially in edible fruits have been found to possess various pharmacological activities for example proanthocyanidin extracts of Vitis vinifera (Vitaceae) and ethanolic fraction of Litchi chinensis (Sapindaceae) fruits have been reported to exhibit potential antioxidant, anti carcinogenic and antiviral activities [11,12].

Solanum xanthocarpum Schrad. \& Wendl (Solanaceae) is an annual herb which grows as wild plant in many parts of India. In vernacular it is known as Kantakari or Bhatkatiya. Fruits are berry, yellow or with white green strips, surrounded by enlarged calyx. Fruits are edible and local people of Manipur (India) use it as folk medicine for treatment of various ailments. Irula tribes of Hasanur Hills (Tamil Nadu, India) have history of consuming the cooked unripe fruits of $S$. xanthocarpum (Sx) as vegetable [13]. In Kerala, the Kattunaikka, Paniya and Kuruma tribes of Wayanad district consume fruits and seeds as food [14]. Fruits are considered as a valuable herbal product for traditional healers in treatment of many common diseases in other parts of India. In Ayurveda, medicinal use of Sx is well documented. Phytoconstituents present in Sx are used as anti-fertility, anti-inflammatory, anti-allergic agents and as potential fungicide $[15,16]$. Present manuscript reports the in vitro antioxidant, cytotoxic and anti-HIV activities of various polar and non-polar extracts of S. xanthocarpum fruit.

\section{Methods}

Plant material and preparation of extracts

S. xanthocarpum (Sx) fruits were collected from village Lalapur, Allahabad and were identified by experts in Botany Department, University of Allahabad, Allahabad, India. The voucher specimen has been kept in our department (AU/BCH/AKP/08). The fruits were shadedried at room temperature and ground into fine powder. Powdered sample was sequentially extracted with different solvents i.e., hexane (HX), benzene (BZ), chloroform $(\mathrm{CH})$, ethyl acetate (EA), acetone(AC), ethyl alcohol (ET) and water $(\mathrm{AQ})$ in Soxhlet apparatus for $8 \mathrm{~h}[17,18]$.
The extract was centrifuged, filtered and dried under reduced pressure. The residues were dissolved in DMSO for assessment of biochemical activities of extracts.

\section{Thin layer chromatography (TLC)}

TLC plates coated with silica gel G were prepared, dried and activated at $110^{\circ} \mathrm{C}$ for $90 \mathrm{~min}$. The extracts were dissolved in respective solvents and spots were applied with the help of fine capillary tubes. Chloroform-ethyl acetateformic acid (163:63:25) was used as the solvent system [19]. The phytoconstituents were visualized as bands after spraying with $10 \% \mathrm{H}_{2} \mathrm{SO}_{4}$ and retardation factor ( $\mathrm{Rf}$ value) was calculated. Water soluble phenolic contents were further identified as bluish bands after spraying with folin ciocalteau reagent (FCR 1:1 in water).

\section{DPPH radical scavenging assay on TLC plates}

The radical scavenging assay was performed by the method of Cavin et al. [20]. The plate was sprayed with 0.2\% 1,1-diphenyl-2-picrylhydrazyl (DPPH) methanolic solution followed by incubation in dark at room temperature for $30 \mathrm{~min}$. The bands having free radical scavenging capability were identified as yellow spots against a purple background and Rf value was calculated.

\section{Spectroscopic scanning}

The water soluble phenolic spots were eluted in respective solvents and scanned at different wave lengths (250, $280,320,370$ and $510 \mathrm{~nm}$ ) to identify presence of various phenolic groups of compounds such as isoflavones, flavanones, cinnamic acid, chalcones and flavones etc.

\section{Quantitative determination of total flavonoid content}

Aluminum chloride colorimetric method of Chang et al. [21] as modified by us [16] was used for determination of flavonoid content. Small amount $(0.2 \mathrm{ml})$ of different test extracts in DMSO $(2 \mathrm{mg} / \mathrm{ml})$ was taken followed by addition of methanol $(1.8 \mathrm{ml}), 10 \%$ aluminum chloride $(0.1 \mathrm{ml}), 1 \mathrm{M}$ potassium acetate $(0.1 \mathrm{ml})$ and distilled water $(2.8 \mathrm{ml})$. Contents were mixed, incubated at room temperature for $30 \mathrm{~min}$ and then absorbance was measured at $415 \mathrm{~nm}$. The calibration curve was prepared with quercetin $(20-200 \mu \mathrm{g})$ and the flavonoid content in the test samples were expressed as $\mu$ g quercetin equivalent/mg sample ( $\mu \mathrm{g} \mathrm{QE} / \mathrm{mg})$.

\section{Reducing power assay}

The reducing power was determined by the method of Oyaizu [22] with slight modifications [3]. One ml extract $(200-1000 \mu \mathrm{g} / \mathrm{ml})$ in DMSO was taken. To each tube $2.5 \mathrm{ml}$ of phosphate buffer $(0.2 \mathrm{M}, \mathrm{pH} 6.6)$ and $2.5 \mathrm{ml}$ of $1 \%$ potassium ferricyanide $\left(\mathrm{K}_{3} \mathrm{Fe}(\mathrm{CN})_{6}\right)$ were added. Tubes were then incubated at $50^{\circ} \mathrm{C}$ for $20 \mathrm{~min}$. The reaction was stopped by adding $2.5 \mathrm{ml}$ of $10 \%$ TCA. One 
$\mathrm{ml}$ of the supernatant was mixed with $1 \mathrm{ml}$ of distilled water and $0.5 \mathrm{ml}$ of $\mathrm{FeCl}_{3}(0.1 \%, \mathrm{w} / \mathrm{v})$ and kept at room temperature for $2 \mathrm{~min}$. The absorbance was measured at $700 \mathrm{~nm}$. Butylated hydroxytoluene (BHT) was used as positive control for comparison.

\section{DPPH radical scavenging assay}

The free radical scavenging activity was measured by DPPH assay [23] as modified by us [2]. The modification included dissolution of extracts in DMSO instead of methanol. Three milliliter of $0.1 \mathrm{mM}$ DPPH solution in methanol was added to $0.5 \mathrm{ml}$ of the extracts $(250,500$, $1000 \mu \mathrm{g} / \mathrm{ml}$ ) dissolved in DMSO. The content was incubated at room temperature for $30 \mathrm{~min}$ in dark and absorbance was measured at $517 \mathrm{~nm}$. The percentage scavenging activities (\% inhibition) was calculated using the following formula

$$
\% \mathrm{I}=[(\mathrm{Ac}-\mathrm{As}) / \mathrm{Ac}] \times 100
$$

where I is inhibition, Ac and As are the absorbance of the control and the sample, respectively.

\section{Lipid peroxidation inhibition (LPOI) assay}

The method described by Halliwell and Gutteridge [24] was followed to determine the amount of malondialdehyde (MDA) formation with slight modifications [25]. Rat kidney homogenate $(10 \% \mathrm{w} / \mathrm{v})$ was prepared in phosphate buffer $(0.1 \mathrm{M}, \mathrm{pH} 7.4$ having $0.15 \mathrm{M} \mathrm{KCl})$. The protective effect of Sx fruit fractions was determined by taking $100 \mu \mathrm{l}$ extract solutions $(2 \mu \mathrm{g} / \mu \mathrm{l})$ prepared in respective solvents and evaporated to dryness followed by addition of $1 \mathrm{ml} \mathrm{KCl}(0.15 \mathrm{M})$ and $0.5 \mathrm{ml}$ of tissue homogenate. Peroxidation was initiated by adding $100 \mu$ ferric chloride $(10 \mathrm{mM})$. After incubation at $37^{\circ} \mathrm{C}$ for $30 \mathrm{~min}$ thiobarbituric acid reactive substances (TBARS) were estimated by adding $2 \mathrm{ml}$ of ice-cold $\mathrm{HCl}$ $(0.25 \mathrm{~N})$ containing 15\% TCA, 0.5\% TBA and 0.5\% BHT to the reaction mixture, followed by heating at $100^{\circ} \mathrm{C}$ for $60 \mathrm{~min}$. The tubes were cooled and centrifuged. The absorbance of the supernatant was measured at $532 \mathrm{~nm}$. The percent LPOI (\%I) was calculated by the equation no. 1 given above.

\section{Anti-HIV activity}

The HIV-RT inhibition was performed by using an RT assay kit (Roche) [26]. The percentage inhibitory activity of RT inhibitors (extracts) was calculated by comparing with a sample that did not contain an inhibitor using following formula:

$$
\% \text { Inhibition }=100-\left[\left(A_{\mathrm{WI}} / A_{\mathrm{WOI}}\right) \times 100\right]
$$

Where $A_{\mathrm{WI}}$ is absorbance of control and $A_{\text {WOI }}$ is absorbance of sample solution.

\section{Cell lines and growth conditions}

Human cancer cell lines namely, lungs (HOP-62) and leukemia (THP-1) cell lines were procured from National Center for Cell Sciences, Pune, India. Cell lines were grown and maintained in RPMI-1640 medium, $\mathrm{pH} 7.4$ with $10 \%$ FCS, 100 units $/ \mathrm{ml}$ penicillin, $100 \mu \mathrm{g} / \mathrm{ml}$ streptomycin and $2 \mathrm{mM}$ glutamine. Cells were grown in $\mathrm{CO}_{2}$ incubator (Heraeus, GmbH Germany) at $37^{\circ} \mathrm{C}$ in the presence of $90 \%$ humidity and $5 \% \mathrm{CO}_{2}$.

\section{Cytotoxic assay by sulforhodamine B dye (SRB assay)}

The in vitro cytotoxicity of fruit extracts was determined using sulforhodamine-B (SRB) assay [27]. Cell suspension $(100 \mu \mathrm{l})$ was incubated for $24 \mathrm{~h}$. $100 \mu \mathrm{l}$ test extract in DMSO $(100 \mu \mathrm{g} /$ well $)$ was then added to the wells and cells were further incubated for another $48 \mathrm{~h}$. The cell growth was arrested by layering $50 \mu \mathrm{l}$ of $50 \%$ TCA and incubated at $4{ }^{\circ} \mathrm{C}$ for an hour followed by washing with distilled water and air-dried. SRB (100 $\mu \mathrm{l}, 0.4 \%$ in $1 \%$ acetic acid) was added to each well and plates were incubated at room temperature for $30 \mathrm{~min}$. The unbound SRB dye was washed with $1 \%$ acetic acid and plates were air dried. Bound dye was dissolved in Tris- $\mathrm{HCl}$ buffer (100 $\mu \mathrm{l}, 0.01 \mathrm{M}, \mathrm{pH} 10.4)$ and the absorbance was recorded on ELISA reader at $540 \mathrm{~nm}$. Suitable blanks and positive controls were also included.

\section{Statistical analysis}

All experiments were carried out in triplicate and data were expressed as mean \pm standard deviation (SD) or standard error of mean (SEM). The plots were prepared using Microsoft excel and Graph pad Prism software. Data were analyzed using One-way and Two-way ANOVA and the values of $p<0.001$ were considered as statistically significant.

\section{Results}

Thin layer chromatography of extracts

Separation of components is shown in Figure 1A and B. The Rf values of spots are given in Table 1 . Number of spots (Rf 0.03-0.77) on chromatogram became visible after treatment with $10 \% \mathrm{H}_{2} \mathrm{SO}_{4}$. Many non-polar fractions exhibited bands having similar mobility (Rf 0.22 and 0.42). Polar fractions (AC and ET) also revealed components having similar $\mathrm{Rf}$ value $(0.27)$. FCR treatment exhibited presence of water soluble phenolics in $\mathrm{AC}, \mathrm{ET}$ and AQ extracts (Figure $1 \mathrm{C}$ and Table 1).

Many phytoconstituent spots on TLC plates exhibited appreciable DPPH radical scavenging activity (Figure 1D) and their Rf values are shown in Table 1.

\section{Spectroscopic scanning}

Spectroscopic scanning data of water soluble phenolic spots eluted from TLC chromatogram (Figure 1C) are 


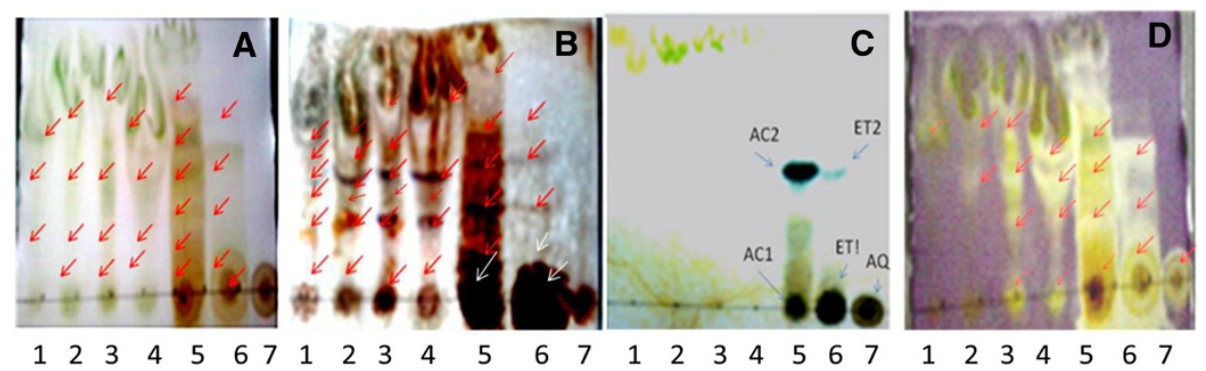

Figure 1 Thin layer chromatogram of S. xanthocarpum fruit extracts. (A) Untreated, (B) Treated with $10 \% \mathrm{H}_{2} \mathrm{SO}_{4}$, (C) Water soluble phenolics (D) Plate assay for DPPH radical scavenging activity of separated components. Numbers 1-7 indicate hexane, benzene, chloroform, ethyl acetate, acetone, ethyl alcohol and water extracts, respectively.

shown in Table 2. AQ and AC1 spots exhibited maximum absorbance at $280 \mathrm{~nm}$ while rest of the spots (ET1, ET2 and AC2) showed absorption maxima at $250 \mathrm{~nm}$. None of the fractions demonstrated absorbance at $510 \mathrm{~nm}$.

\section{Yield of the extracts and total flavonoid content}

The yield of $S$. xanthocarpum fruit extracts increased with polarity of the solvents used for extraction in the order $\mathrm{HX}(0.1 \%), \mathrm{BZ}(0.2 \%), \mathrm{CH}(0.4 \%), \mathrm{EA}(7 \%), \mathrm{AC}$ (5\%), ET (12\%) and AQ (38\%). Extracts were quantified for total flavonoid contents (Table 1). EA extract accounted for maximum flavonoid content (162.49 \pm $0.15 \mu \mathrm{g} \mathrm{QE} / \mathrm{mg}$ ) followed by AC extract (148.07 \pm $0.18 \mu \mathrm{g} \mathrm{QE} / \mathrm{mg})$. The order of flavonoid content in extracts was $\mathrm{EA}, \mathrm{AC}, \mathrm{HX}, \mathrm{ET}, \mathrm{BZ}, \mathrm{CH}$ and $\mathrm{AQ}$.

\section{Reducing power of extracts}

Concentration dependent (200-1000 $\mu \mathrm{g} / \mathrm{ml}$ ) reducing ability was observed (Figure 2A). At higher concentration the reducing activities of $\mathrm{CH}, \mathrm{ET}$ and $\mathrm{AQ}$ extracts was $0.568,0.559$ and 0.563 , respectively. The reducing power of potential Sx fruit extracts was comparable to the activity shown by BHT.

\section{DPPH radical scavenging activity}

Free radical scavenging activity of Sx fruit extracts are shown in Figure 2B. Most of the extracts demonstrated appreciable radical scavenging potential (about 80\%) even at lowest test concentration $(250 \mu \mathrm{g} / \mathrm{ml})$. Further increase in concentration led to saturation effect (7492\%). Standard antioxidants namely BHA, BHT, quercetin and ascorbic acid have already been reported to produce $95-99 \%$ scavenging activities [2].

\section{Protective effect of extracts against lipid peroxidation}

Lipo protective efficacy (\% LPOI) of extracts against peroxidative damage in tissue homogenate is shown in Figure 2C. Non-polar fractions exhibited 48-55\% protection against peroxidation while other fractions accounted for less than 30\% activity. Butylated hydroxy anisole (BHA) displayed about $63 \%$ protection against membrane damage.

\section{Anti-HIV activity}

Sx fruit extracts were monitored for anti-RT activity at different concentrations $(0.6$ and $6.0 \mu \mathrm{g} / \mathrm{ml})$. Non polar extracts showed dose dependent inhibitory activity. The anti-HIV RT activity in general was low as shown in Figure 3A. Nevirapine, the standard anti-HIV drug

Table 1 Total flavonoid content in S. xanthocarpum fruit extracts and Rf value of spots on chromatogram

\begin{tabular}{|c|c|c|c|c|c|c|c|c|c|}
\hline Extracts & Flavonoids ( $\mu \mathrm{g} \mathrm{QE} / \mathrm{mg})$ & & & & & & & & \\
\hline $\mathrm{HX}$ & $71.82 \pm 0.08$ & $0.05^{\mathrm{b}}$ & $0.22^{\mathrm{a}}$ & $0.35^{\mathrm{b}}$ & $0.42^{\mathrm{a}}$ & $0.50^{\mathrm{b}}$ & $0.59^{\mathrm{ad}}$ & - & - \\
\hline$B Z$ & $69.76 \pm 0.12$ & $0.05^{\mathrm{a}}$ & $0.22^{\mathrm{a}}$ & $0.35^{\mathrm{b}}$ & $0.42^{\mathrm{ad}}$ & $0.51^{\mathrm{b}}$ & $0.64^{\mathrm{ad}}$ & - & - \\
\hline $\mathrm{CH}$ & $59.51 \pm 0.13$ & $0.03^{\mathrm{bd}}$ & $0.05^{\mathrm{a}}$ & $0.22^{\mathrm{ad}}$ & $0.35^{\mathrm{b}}$ & $0.42^{\mathrm{ad}}$ & $0.53^{\mathrm{b}}$ & $0.70^{\mathrm{ad}}$ & - \\
\hline EA & $162.49 \pm 0.15$ & $0.06^{\mathrm{ad}}$ & $0.22^{\mathrm{ad}}$ & $0.35^{\mathrm{b}}$ & $0.42^{\mathrm{ad}}$ & $0.62^{\mathrm{bd}}$ & $0.71^{\mathrm{a}}$ & - & - \\
\hline$A C$ & $148.07 \pm 0.18$ & $0.05^{\mathrm{acd}}$ & $0.14^{\mathrm{a}}$ & $0.27^{\mathrm{ad}}$ & $0.31^{\mathrm{b}}$ & $0.44^{\mathrm{ad}}$ & $0.57^{\text {acd }}$ & $0.69^{\mathrm{a}}$ & $0.77^{b}$ \\
\hline ET & $71.43 \pm 0.14$ & $0.05^{\mathrm{acd}}$ & $0.14^{\mathrm{b}}$ & $0.27^{\mathrm{ad}}$ & $0.45^{\mathrm{ad}}$ & $0.58^{\mathrm{acd}}$ & - & - & - \\
\hline $\mathrm{AQ}$ & $10.22 \pm 0.12$ & $0.00^{\mathrm{acd}}$ & - & - & - & - & - & - & - \\
\hline
\end{tabular}

Abbreviations: $H X$ hexane, $B Z$ benzene, $C H$ chloroform, $E A$ ethyl acetate, $A C$ acetone, $E T$ ethyl alcohol, $A Q$ water.

Values with superscript ${ }^{a \prime}$ indicates spots on the untreated chromatogram; 'b' indicates additional spots visualized after $10 \% \mathrm{H}_{2} \mathrm{SO}_{4}$ treatment; ${ }^{c}{ }^{\prime \prime}$ indicates water soluble phenolics after treatment with FCR reagent (1:1 in water); and 'd denotes phytoconstituent spots having DPPH radical scavenging ability. 
Table 2 Spectroscopic scanning data of water soluble phenolic spots obtained from thin layer chromatogram of $S$. xanthocarpum fruit extracts

\begin{tabular}{llllll}
\hline $\begin{array}{l}\text { Wavelength } \\
\text { (nm) }\end{array}$ & \multicolumn{6}{l}{ Absorbance } \\
\cline { 2 - 6 } & $\mathbf{A Q}$ & $\mathbf{E T}_{\mathbf{1}}$ & $\mathbf{E T}_{\mathbf{2}}$ & $\mathbf{A C}_{\mathbf{1}}$ & $\mathbf{A C}_{\mathbf{2}}$ \\
\hline 250 & 0.1880 & 4.0000 & 3.5042 & - & 4.0000 \\
280 & 0.2897 & - & 0.0851 & 4.0000 & - \\
320 & 0.0309 & 1.0752 & 0.8752 & 0.6494 & 0.5701 \\
370 & - & - & 0.5432 & 0.3420 & 0.4990 \\
510 & - & - & - & - & - \\
\hline
\end{tabular}

Abbreviations: $A Q$ water, $E T$ ethyl alcohol, $A C$ acetone exracts.

(not shown in figure) demonstrated $99.67 \%$ inhibitory activity.

\section{Cytotoxic activity}

The cytotoxic activity of extracts against HOP-62 (lung) and THP-1 (leukemia) are depicted in Figure 3B. Non polar extracts ( $\mathrm{HX}, \mathrm{BZ}, \mathrm{CH}$ and $\mathrm{EA}$ ) exhibited considerable anticancer potential showing $85-91 \%$ growth inhibition of THP-1 cell line while $\mathrm{BZ}$ and $\mathrm{CH}$ fractions accounted for about $70 \%$ cytotoxicity against lung cancer cell line (HOP-62). Polar extracts in general displayed lower cytotoxic activity.

\section{Discussion}

Plants are natural repositories of molecules with diverse structure and function. Many phytoconstituents exhibit nutritive and pharmacological activities [28-30]. In the current study compounds present in sequential extracts of S. xanthocarpum fruit were screened for their biochemical potential such as antioxidant, cytotoxic and anti-HIV activities. Thin layer chromatography enables the fractionation and identification of secondary compounds (Figure 1, Table 1). AC fraction showed maximum variability of phyto-constituents as indicated by number of spots. In non polar fractions ( $\mathrm{HX}$ and $\mathrm{CH}$ ) more spots became visible after treatment with $\mathrm{H}_{2} \mathrm{SO}_{4}$. It could be inferred that phytoconstituents in $\mathrm{HX}$ and $\mathrm{CH}$ fractions might have absorption in UV range. A single wavelength is not enough to study mixture of phenolic compounds because different polyphenols show absorption at specific wave lengths. Isoflavones and benzoic acids absorb at $250 \mathrm{~nm}$; flavanones, catechins, ellagic acid and flavones at $280 \mathrm{~nm}$; cinnamic acids, flavones and chalcones at $320 \mathrm{~nm}$; flavonols at $370 \mathrm{~nm}$ and anthocyanins absorb at $510 \mathrm{~nm}$ [31-33]. Spectroscopic scanning of water soluble phenolic spots (AC, ET and AQ) showed maximum absorbance at 250 and $280 \mathrm{~nm}$ (Figure 1C, Table 2). Absorption maxima for ET1, ET2 and AC2 spots at $250 \mathrm{~nm}$ indicates the presence of isoflavones and/or benzoic acid while AQ and
AC1 absorbed maximally at $280 \mathrm{~nm}$ indicating presence of flavanones, flavones, catechins and/or ellagic acid. Besides absorption at 250 and $280 \mathrm{~nm}$, all the water soluble phenolic spots also showed absorbance at $320 \mathrm{~nm}$ indicating presence of cinnamic acid, chalcones and flavones in the extracts (Table 2).

EA and AC extracts of fruit were found to have noticeable quantity of flavonoid content (Table 1). Chemically flavonoids are diphenylpropanes and more than 4000 flavonoids have been isolated from plants [33]. Many biological activities such as lipoprotective, anti platelet, and anti inflammatory are related to the antioxidative effects of flavonoids [16]. The mechanism behind antioxidant property of flavonoids includes radical scavenging, reducing ability, metal ion chelation and inhibition of enzymatic systems responsible for free radical generation [33].

Violet colour of DPPH, the commercially available stable free radical, is reduced to a pale yellow colour due to the abstraction of hydrogen atom from antioxidant compound. Appearance of yellow coloured spots against purple background in TLC-DPPH plate assay indicated potential antioxidant activity in many sub fractions of EA, AC and ET extracts as well as in AQ sample (Figure 1D, Table 1). The intensity of the yellow colour depends on the quantity and the nature of the compounds present at that location [20]. In quantitative DPPH radical scavenging assay most of the Sx fruit extracts except $\mathrm{HX}$ and $\mathrm{BZ}$ demonstrated appreciable radical scavenging activity at $250 \mu \mathrm{g} / \mathrm{ml}$ concentration revealing considerable antioxidant potential in the extracts (Figure 2B). Our findings are corroborated by the reports on other plants that $\mathrm{DPPH}$ radical scavenging activity of extracts is mediated by their hydrogen donating ability [34,35]. Both the assays i.e., qualitative (DPPH-TLC) and quantitative (DPPH) assays substantiate the prospective use of $S$. xanthocarpum fruit as a food having potent antioxidant activity. A weak positive correlation between flavonoid content and DPPH radical scavenging activity was observed (Figure 4A). Prasad et al. [36] have also reported a weak correlation between flavonoid content and the radical scavenging activity.

Reducing power of plant extracts is generally associated with the presence of reductones, which exert antioxidant action by breaking the free radical chain through donating a hydrogen atom [37]. In this assay, $\mathrm{Fe}^{3+} /$ ferricyanide complex is reduced to the blue colored ferrous form by antioxidants with absorption maxima at $700 \mathrm{~nm}$ [37]. Some of the extracts in present study exhibited considerable reducing power at higher concentrations indicating their hydrogen donating capacity (Figure 2A). A negative correlation was found between flavonoid content and the reducing power of the extracts 


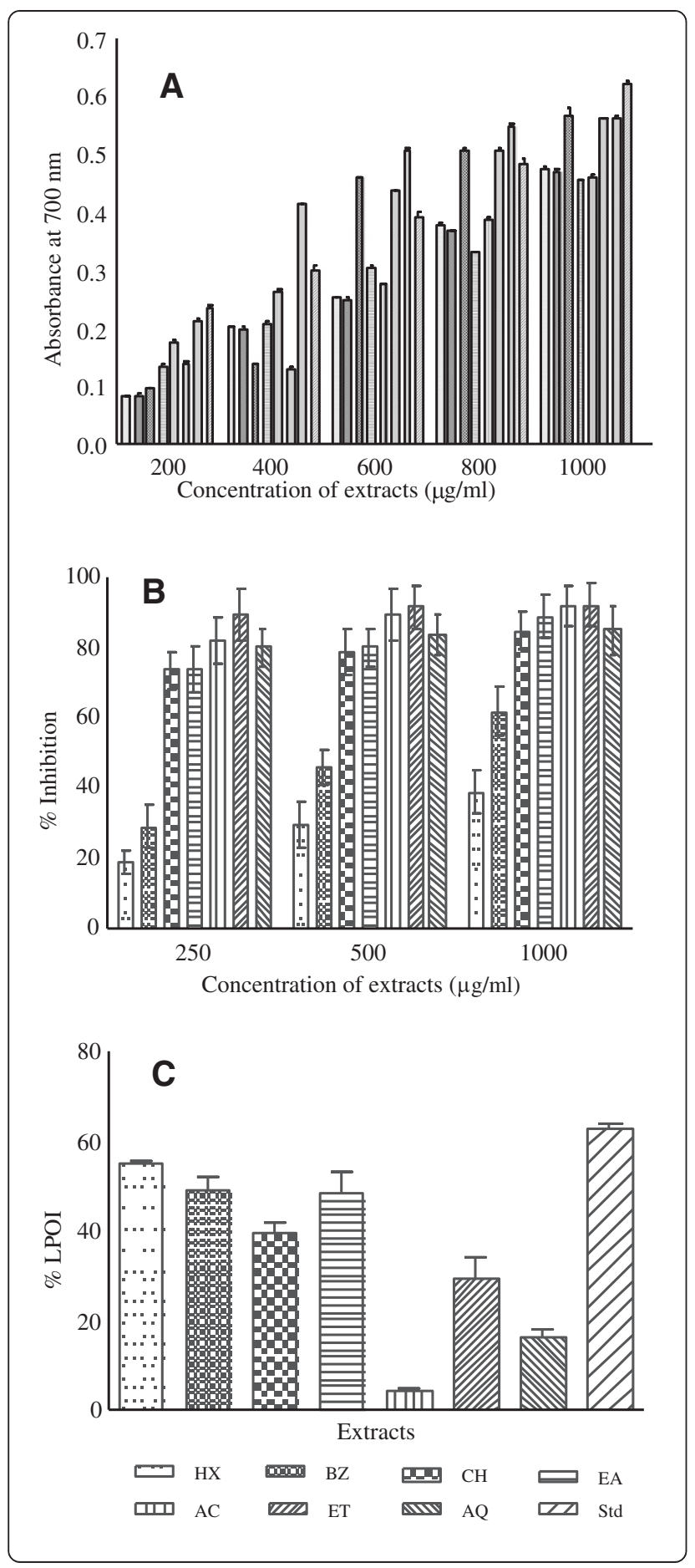

(Figure 4B) which is supported by the report of Liu et al. [38]. However a positive correlation between reducing power and radical scavenging ability of the extracts was found (Figure 4B). Since both the properties are due to hydrogen donating ability of the test sample it might be concluded that in addition to flavonoids there are other phytochemical moieties responsible for the antioxidant potential of S. xanthocarpum fruit extracts [39].

Redox chemistry of iron plays an important role in the occurrence and the rate of lipid peroxidation. $\mathrm{Fe}^{3+}$ reacts with lipid hydroperoxides to form peroxyl radicals which ultimately results in malondialdehyde (MDA) formation. MDA is usually taken as a marker of LPO and oxidative stress [40]. Some of the non-polar extracts accounted for about 40-55\% lipo-protective activities (Figure 2C). This revealed that major phytoconstituents present in the active extracts are responsible for quenching $\mathrm{Fe}^{3+}$ and thereby preventing oxidative damage to lipids and in turn protecting the tissues [24,25]. Phenolics have been shown to delay or prevent the progression of various diseases by averting peroxidation of membrane lipids $[8,35]$.

ROS can cause DNA damage and has been implicated in carcinogenesis [41]. S. xanthocarpum extracts showed potent cytotoxic activities against leukemia cell line (THP-1). However lower activity was observed against lung cancer cell line (HOP-62). This may be attributed to the fact that different cell lines might exhibit different sensitivities to cytotoxic agents [42]. The results revealed a positive correlation between flavonoid content and THP-1 cell line growth inhibition (Figure 4A). Similar relationship between flavonoids and cytotoxic activities has also been reported in other studies [43]. Flavonoids acting as antioxidants have been reported to inhibit carcinogenesis. The position, number, and substitution of the hydroxyl of the rings in flavonoid may be important factors affecting their cytotoxic activities [33]. Some of the flavonoids such as apigenin, fisetin, quercetin and 


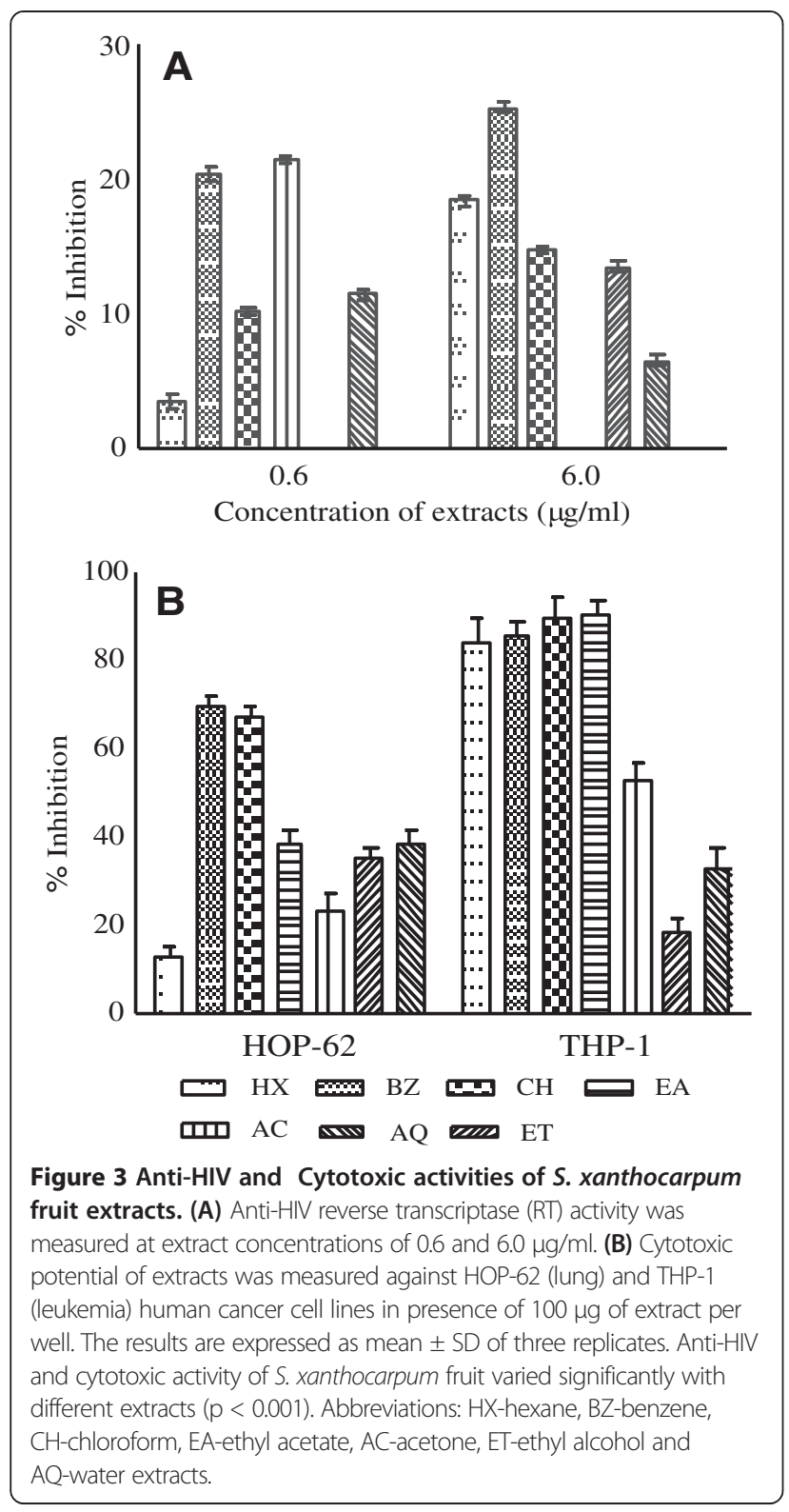

luteolin are known to be potent inhibitors of cancer cell proliferation $[7,39,44]$. There are several mechanisms of the cytotoxicity of flavonoids, including the inhibition of topoisomerases and kinases [33].

Natural products have been shown to inhibit various stages of the replication cycle of the HIV [45]. Many viruses reported to be affected by phytochemicals include herpes simplex virus, respiratory syncytial virus, parainfluenza virus, and adenovirus [46]. Phytoconstituents have potential to exhibit both anti infective and anti replicative abilities. S. xanthocarpum fruit extracts in our study exhibited low inhibitory activity against HIV RT. Since numerous chemical moieties (with or without activity) are present in crude extract, it might be possible

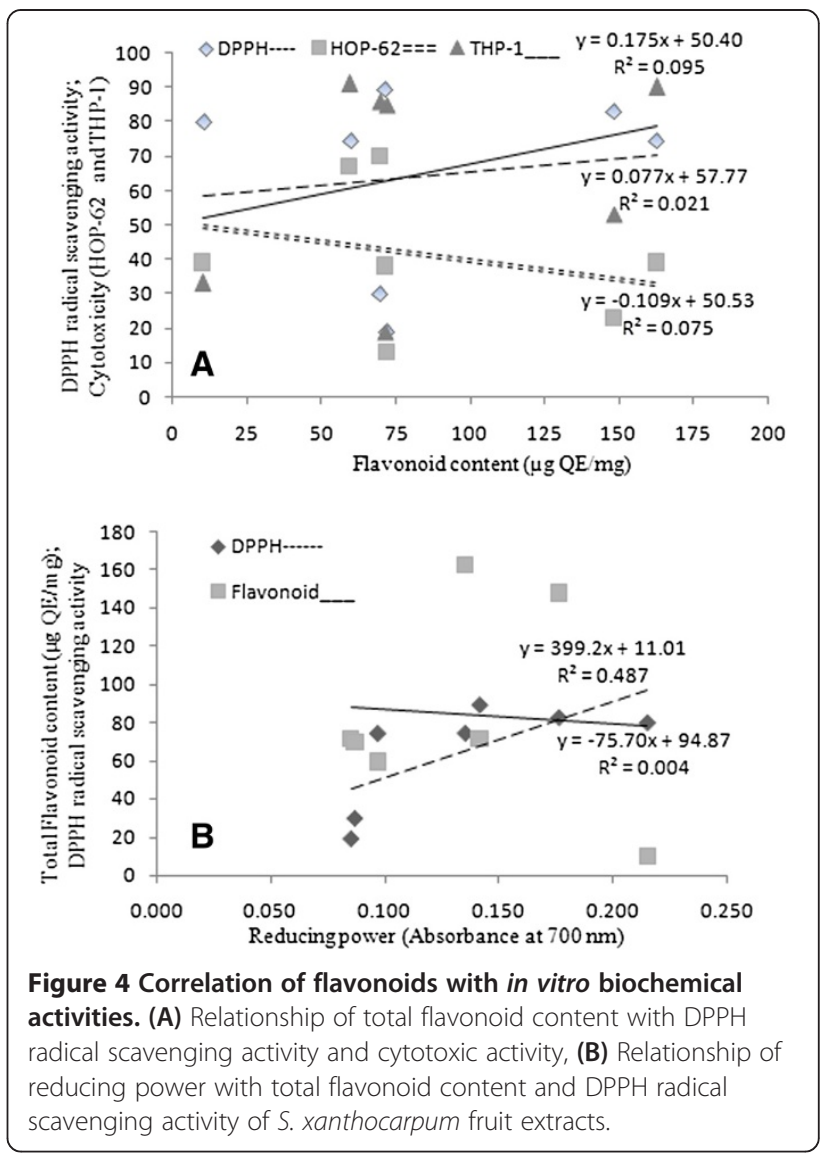

that isolation and purification of the active ingredients from potential extracts may provide enhancement in anti-HIV activity.

\section{Conclusion}

The present study revealed that the phytoconstituents present in S. xanthocarpum fruit possess considerable antioxidant and cytotoxic potential. They are potent scavengers of free radicals and have reducing ability. Therefore they prevent ROS mediated lipid damage. The study validated the use of $S$. xanthocarpum fruit by tribal communities in traditional medicine. Isolation and characterization of specific chemical moieties having potential biologic activities may provide an effective antioxidant and anticancer agents in future.

\section{Competing interests}

Authors declare that they do not have any conflict of interests.

\section{Authors' contribution}

AKP participated in the research design, analysis of the data and drafting of the manuscript. SK conducted all the experiments. Both the authors have read and approved the final manuscript.

\section{Acknowledgement}

SK acknowledges financial support from UGC, India in the form of Rajiv Gandhi National Senior Research Fellowship. Authors also acknowledge 
Dr. A. K. Saxena, Chief Scientist, Cancer Pharmacology Divison, IIIM Jammu, India for providing necessary help.

Received: 18 December 2013 Accepted: 24 March 2014 Published: 28 March 2014

\section{References}

1. Pham-Huy LA, He H, Pham-Huyc C: Free radicals, antioxidants in disease and health. Int J Biomed Sci 2008, 4:89-96.

2. Mishra A, Kumar S, Bhargava A, Sharma B, Pandey AK: Studies on in vitro antioxidant and antistaphylococcal activities of some important medicinal plants. Cell Mol Biol 2011, 57:16-25.

3. Pandey AK, Mishra AK, Mishra A, Kumar S, Chandra A: Therapeutic potential of C. zeylanicum extracts: an antifungal and antioxidant perspective. Int J Biol Med Res 2010, 1:228-233.

4. Terao J, Piskula MK: Flavonoids as inhibitors of lipid peroxidation in membranes. In Flavonoids in health and disease. Edited by Rice-Evans CA, Packer L. New York: Marcel Dekker; 1997:277-295.

5. Pandey AK, Mishra AK, Mishra A: Antifungal and antioxidative potential of oil and extracts derived from leaves of indian spice plant Cinnamomum tamala. Cell Mol Biol 2012, 58:142-147.

6. Naasani I, Seimiya H, Tsuruo T: Telomerase inhibition, telomere shortening, and senescence of cancer cells by tea catechins. Biochem Biophys Res Commun 1998, 249:391-396.

7. Mishra A, Sharma AK, Kumar S, Saxena AK, Pandey AK: Bauhinia variegata leaf extracts exhibit considerable antibacterial, antioxidant and anticancer activities. BioMed Res Int 2013, 2013:915436.

8. Kumar S, Chashoo G, Saxena AK, Pandey AK: Parthenium hysterophorus: a probable source of anticancer, antioxidant and anti-HIV agents. BioMed Res Int 2013, 2013:810734.

9. Rawal RK, Tripathi R, Katti SB, Pannecouque C, De Clercq E: Design, synthesis, and evaluation of 2-aryl-3-heteroaryl-1,3- thiazolidin-4-ones as anti-HIV agents. Bioorg Med Chem 2007, 15:1725-1731.

10. Hsieh PW, Chang FR, Lee KH, Hwang TL, Chang SM, WU YC: A new anti-HIV alkaloid, drymaritin, and a new C-glycoside flavanoid, diandraflavone from Drymaria diandra. J Nat Prod 2004, 67:1175-1177.

11. Ye X, Krohn RL, Liu W, Joshi SS, Kuszynski CA, McGinn TR, Bagchi M, Preuss HG, Stohs SJ, Bagchi D: The cytotoxic effects of a novel IH636 grape seed proanthocyanidin extract on cultured human cancer cells. Mol Cell Biochem 1999, 19:699-108.

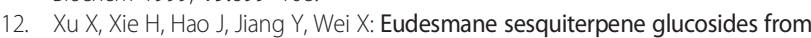
lychee seed and their cytotoxic activity. Food Chem 2010, 123:1123-1126.

13. Revathi P, Parimelazhagan T: Traditional knowledge on medicinal plants used by the Irula tribe of Hasanur hills, Erode District, Tamil Nadu, India. Ethnobot Leaflets 2010, 14:136-160.

14. Narayanan MKR, Anilkumar N, Balakrishnan V, Sivadasan M, Alfarhan HA, Alatar AA: Wild edible plants used by the Kattunaikka, Paniya and Kuruma tribes of Wayanad District, Kerala, India. J Med Plants Res 2011, 5:3520-3529.

15. Singh OM, Singh TP: Phytochemistry of Solanum xanthocarpum: an amazing traditional healer. J Sci Ind Res 2010, 69:732-740.

16. Kumar S, Sharma UK, Sharma AK, Pandey AK: Protective efficacy of Solanum xanthocarpum root extracts against free radical damage: phytochemical analysis and antioxidant effect. Cell Mol Biol 2012, 58:174-181.

17. Pandey AK: Anti-staphylococcal activity of a pan-tropical aggressive and obnoxious weed Parthenium hysterophorus: an in vitro study. Natl Acad Sci Lett 2007, 30:383-386.

18. Mishra AK, Mishra A, Kehri HK, Sharma B, Pandey AK: Inhibitory activity of Indian spice plant Cinnamomum zeylanicum extracts against Alternaria solani and Curvuluria lunata, the pathogenic dematiaceous moulds. Ann Clin Microbiol Antimicrobials 2009, 8:9.

19. Kumar S, Mishra A, Pandey AK: Antioxidant mediated protective effect of Parthenium hysterophorus against oxidative damage using in vitro models. BMC Comp Alt Med 2013, 13:120.

20. Cavin A, Hostettmann K, Dyatmyko W, Potterat O: Antioxidant and lipophilic constituents of Tinospora crispa. Planta Med 1998, 64:393-396.

21. Chang $\mathrm{C}$, Yang $\mathrm{M}$, Wen $\mathrm{H}$, Chern J: Estimation of total flavonoid content in propolis by two complementary colorimetric methods. J Food Drug Anal 2002, 10:178-182

22. Oyaizu M: Studies on products of browning reactions: antioxidative activities of products of browning reaction prepared from glucosamine. Jap J Nut 1986, 44:307-315.
23. Singh RP, Murthy CKN, Jayapakash GK: Studies on the antioxidant activity of Pomegranate (Punica granatum) peel and seed extracts using in vitro models. J Agric Food Chem 2002, 50:81-86.

24. Halliwell B, Gutteridge JNC: Mechanism of damage of cellular targets by oxidative stress: lipid peroxidation. In Free Radicals in Biology and Medicine. Edited by Halliwell B, Gsutteridge JMC. Oxford, UK: Oxford University Press: 1999:284-313.

25. Kumar S, Pandey AK: Antioxidant, lipo-protective and antibacterial activities of phytoconstituents present in Solanum xanthocarpum root. Int Rev Biophysical Chem 2012, 3:42-47.

26. Reverse Transcriptase Assay: Colorimetric kit, Roche Diagnostics GmbH. Mannheim, Germany: Roche Applied Science.

27. Skehan P, Storeng R, Scudiero D, Monks A, McMohan J, Vistica D, Warren JT, Bokesh H, Kenny S, Boyd M: New colorimetric cytotoxicity assay for anticancer drug screening. J Natl Cancer Inst 1990, 82:1107-1112.

28. Maurya A, Chauhan P, Mishra A, Pandey AK: Surface functionalization of $\mathrm{TiO}_{2}$ with plant extracts and their combined antimicrobial activities against E. faecalis and E. coli. J Res Updates Polymer Sci 2012, 1:43-51.

29. Mishra AK, Mishra A, Bhargava A, Pandey AK: Antimicrobial activity of essential oils from the leaves of Cinnamomum spp. Natl Acad Sci Lett 2008, 31:341-345.

30. Pandey AK, Pandey P, Sharma S, Maheshwari DK: Antibacterial potential of extracts of Lantana camara - A prominent weed of northern India. Universities J Phytochem Ayur Heights 2005, 1:18-23.

31. Sakakibara $H$, Honda $Y$, Nakagawa $S$, Ashida $H$, Kanazawa A: Simultaneous determination of all polyphenols in vegetables, fruits, and teas. J Agric Food Chem 2003, 51:571-581

32. Stalikas CD: Extraction, separation, and detection methods for phenolic acids and flavonoids. J Sep Sci 2007, 30:3268-3295.

33. Kumar S, Pandey AK: Chemistry and biological activities of flavonoids: An Overview. Sci World J 2013, 2013:162750.

34. Jayaprakasha GK, Girennavar B, Patil BS: Radical scavenging activity of Rio red grapefruits and sour orange fruit extracts in different in-vitro model system. Biores Technol 2008, 99:4484-4494.

35. Kumar S, Gupta A, Pandey AK: Calotropis procera root extract has capability to combat free radical mediated damage. ISRN Pharmacol 2013, 2013:691372.

36. Prasad KN, Yang B, Dong $X$, Jiang G, Zhang $H$, Xie $H$, Jiang Y: Flavonoid contents and antioxidant activities from Cinnamomum species. Inn Food Sci Emerg Technol 2009, 10:627-632.

37. Kumar S, Pandey AK: Phenolic content, reducing power and membrane protective activities of Solanum xanthocarpum root extracts. Vegetos 2013, 26:301-307.

38. Liu H, Qiu N, Ding H, Yao R: Polyphenols contents and antioxidant capacity of 68 Chinese herbals suitable for medical or food uses. Food Res Int 2008, 41:363-370.

39. Mishra A, Kumar S, Pandey AK: Scientific validation of the medicinal efficacy of Tinospora cordifolia. Sci World J 2013, 2013:292934.

40. Janero DR: Malondialdehyde and thiobarbituric acid reactivity as diagnostic indices of lipid peroxidation and peroxidative tissue injury. Free Rad Biol Med 1990, 9:515-540.

41. Loft S, Poulsen HE: Cancer risk and oxidative DNA damage in man. $J$ Mol Med 1996, 74:297-312.

42. Kaur K, Michael H, Arora S, Harkonen P, Kumar S: In vitro bioactivity-guided fractionation and characterization of polyphenolic inhibitory fractions from Acacia nilotica (L.) Willd, ex Del. J Ethnopharmacol 2005, 99:353.

43. Pittella F, Dutra RC, Junior DD, Lopes MTP, Barbosa NR: Antioxidant and cytotoxic activities of Centella asiatica (L) Urb. Int J Mol Sci 2009, 10:3713-3721.

44. Fotsis T, Pepper MS, Aktas E: Flavonoids, dietary-derived inhibitors of cell proliferation and in vitro angiogenesis. Cancer Res 1997, 57:2916-21.

45. Vlietinck AJ, Bruyne DT, Apers S, Pieters LA: Plant-derived leading compounds for chemotherapy of human immunodeficiency virus (HIV) infection. Planta Med 1998, 64:97-109.

46. Wang HK, Xia Y, Yang ZY, Natschke SL, Lee KH: Recent advances in the discovery and development of flavonoids and their analogues as antitumor and anti-HIV agents. Adv Exp Med Biol 1998, 439:191-225.

doi:10.1186/1472-6882-14-112

Cite this article as: Kumar and Pandey: Medicinal attributes of Solanum xanthocarpum fruit consumed by several tribal communities as food: an in vitro antioxidant, anticancer and anti HIV perspective. BMC

Complementary and Alternative Medicine 2014 14:112. 